\title{
Experiment and Dynamic Simulation of Cervical Tractions in Inclined and Sitting Positions
}

\author{
Lawrence K. F. Wong1, Zhiwei Luo', Nobuyuki Kurusu², Keiji Fujino³ \\ ${ }^{1}$ Graduate School of System Informatics, Kobe University, Kobe, Japan \\ ${ }^{2}$ Kobe Factory of Minato Medical Science Co., LTD., Kobe, Japan \\ ${ }^{3}$ Fujino Orthopedics Hospital, Hamamatsu, Japan \\ Email: wonglawrence@cs11.cs.kobe-u.ac.jp
}

How to cite this paper: Wong, L.K.F., Luo, Z.W., Kurusu, N. and Fujino, K. (2017) Experiment and Dynamic Simulation of Cervical Tractions in Inclined and Sitting Positions. Open Journal of Therapy and Rehabilitation, 5, 83-97.

https://doi.org/10.4236/ojtr.2017.53008

Received: May 4, 2017

Accepted: July 15, 2017

Published: July 18, 2017

Copyright $\odot 2017$ by authors and Scientific Research Publishing Inc. This work is licensed under the Creative Commons Attribution International License (CC BY 4.0).

http://creativecommons.org/licenses/by/4.0/

\begin{abstract}
This study aims to validate the accuracy of a cervical traction therapy simulation model by comparing the intervertebral separations of six asymptomatic male adults when traction was applied to their cervical spines. The subjects were tested on two mechanical traction devices, representing the inclined and sitting positions. A total of 55 radiographic images of their cervical spines were taken before and during traction. The result showed statistically significant intervertebral space changes in the inclined position but the changes in the sitting position were not statistically significant. The observed changes of the cervical spine were used to adjust parameters of the traction therapy model, which contains a human model with cervical spine built with springs and dampers and two traction devices in inclined and sitting positions. A series of traction forces and traction angles were applied to the model to simulate the actual parameters used in the experiment and the new model was used to evaluate the two traction positions. The result suggested that inclined position creates greater intervertebral separations on the posterior sides. Differences in separations due to age were not observed in both positions. The result also suggested that the inclined position provides better control in positioning the separations at different spinal segments than the sitting position.
\end{abstract}

\section{Keywords}

Cervical Traction Therapy, Spine, Posture, Dynamic Simulation

\section{Introduction}

Traction therapy, also known as spinal decompression therapy, refers to any medical procedure that applies force along the inferior-superior axis of the spine 
to extend the cervical and lumbar spine. By applying traction or stretch to the regions, these therapies aim to relieve pressure and increase blood flow in the designated area. Traction therapy has been widely used in nonsurgical therapies and rehabilitation to treat chronic neck and back pain caused by herniated discs and other injuries at the cervical and lumbar spine region. Over the years, many studies have proposed various mechanisms to improve the therapeutic effects of cervical traction. Savva et al. [1] found that the application of cervical traction, if combined with neural mobilization, can reduce pain in cervical radiculopathy. Jellad et al. [2] also reported that cervical traction, whether manual or mechanical, contributed in the rehabilitation of cervical radiculopathy if it is included in a multimodal rehabilitation approach. Zylberold et al. [3] evaluated three forms of cervical traction treatment and reported that intermittent traction performed significantly better than the no traction group.

The position and amount of intervertebral space changes are mainly affected by traction force and traction angle. Previous studies [4] [5] have examined how these two factors could affect the efficacy of the therapy. In general, large traction force can achieve greater separation. Traction angle, on the other hand, helps to control the location of the separation to target the injured area. However, it is worth noting that traction position can also play a role in controlling intervertebral space changes. Traction position varies in mechanical traction devices and many researchers have examined their mechanisms to try to determine how they can affect the efficacy of cervical traction therapy. For instance, Chung et al. [6] compared the intervertebral disc space between axial and anterior lean traction and demonstrated that anterior lean traction in sitting position provided more disc space anteriorly and posteriorly. Fater et al. [7] compared the supine and sitting position using home traction units and concluded that supine cervical traction may be more effective for increasing posterior vertebral separation. Using a dynamic simulation model, Wong et al. [8] also examined the intervertebral separation of inclined and sitting positions and demonstrated that inclined position was able to create greater posterior separation in their model.

While the effect of cervical traction therapy is generally recognized to create intervertebral separations, its exact mechanism still has not been fully understood. Additionally, it is important to investigate the associated changes of the cervical spine during traction to better understand how one can accurately control the position and amount of intervertebral separations for individual patient. By combining a human skeleton model and traction therapy device models into a simulation, the spinal changes during traction therapy can be easily assessed. The difference in traction positions can also be compared.

The purpose of the present study was to improve upon the existing cervical traction therapy model [8] and to investigate the biomechanics of the cervical spine during traction therapy in inclined and sitting positions. Six asymptomatic male adults were recruited for a radiographic study. The subjects were seated on two different mechanical traction devices, representing the inclined and sitting positions. Radiographic images of their cervical spines were taken before and 
during traction. The changes of the intervertebral separations were analyzed and used to adjust the simulation model. The new model was then used to evaluate the two traction positions. We believe this study will provide insight on the benefits and drawbacks of each traction position. It can also serve as a reference for therapists who want to achieve more precise control in cervical traction therapy.

\section{Radiographic Experiment}

\subsection{Experiment Setup}

The radiographic experiment consisted of six asymptomatic Japanese male adults. The age groups $(30 \mathrm{~s} \times 2,50 \mathrm{~s} \times 2,60 \mathrm{~s} \times 2)$ of the subjects were chosen as such to allow us to investigate potential age differences in respect to cervical traction. Subjects were excluded if they had history of cervical-related injuries or related disorders. The experimental procedures and potential risks were explained to all subjects and signed consent forms were obtained before the experiment. The radiographic system (Model: Veradius Neo, Koninklijke Philips N.V.) used in the experiment consisted of a C-arc arm that could take radiographic images and videos when a subject was seated on a traction machine. The experiment was conducted in an X-ray laboratory under the supervision of a medical doctor and a radiologist. The study was approved by an ethics research committee of Kobe University prior to data collection. Figure 1 shows a subject in inclined position during the experiment.

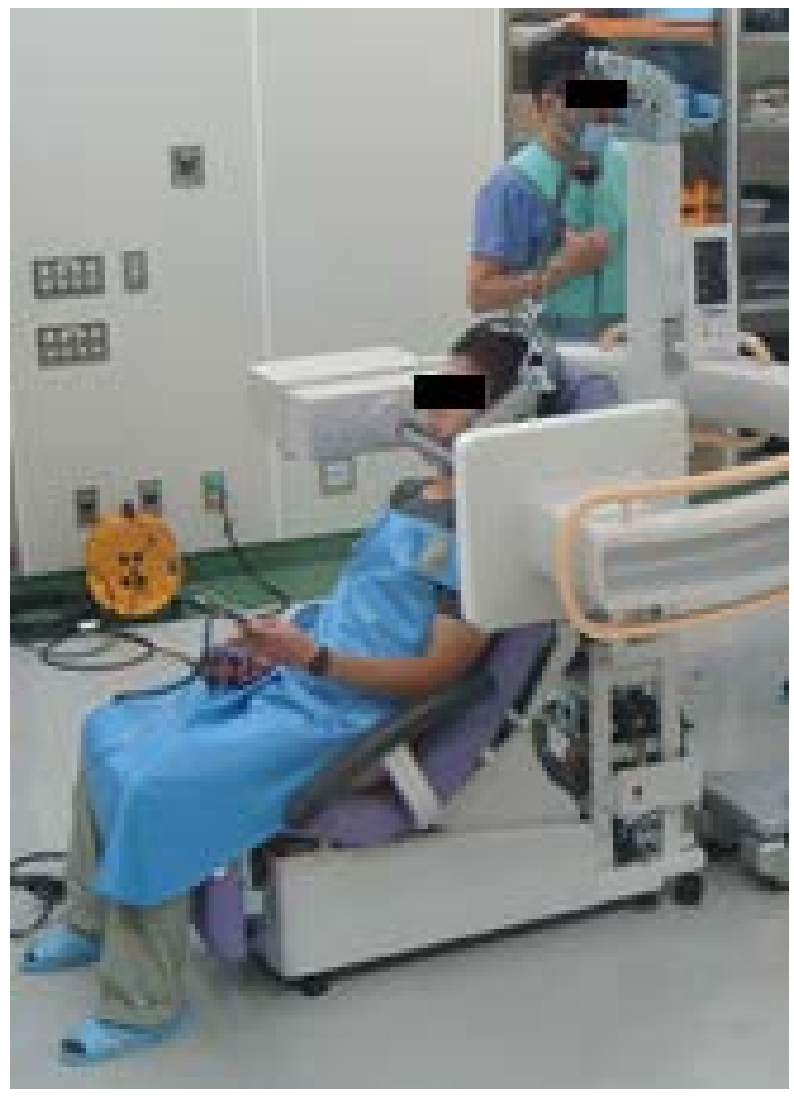

Figure 1. Cervical traction in inclined position during radiographic experiment. 
Two mechanical traction devices [9] [10] were set up in a radiographic room for radiographic assessments, representing the inclined and sitting positions respectively. In the inclined position, the subject sits on a motorized seat with his head attached to the halter. Byrotating the seat around the horizontal axis along the sagittal plane, traction angles between $10^{\circ}$ and $40^{\circ}$ can be achieved. In the sitting position, the subject sits up right on a fixed chair with his head attached to a head halter. Traction angles are adjusted by changing the length of the top metal bar. The head halter included two straps offering support to the chin and occiput during cervical traction. The movements of the two traction devices are illustrated in Figure 2. On both machines, the vertex of the traction angle was set at the base of the neck, near the position of the first thoracic vertebra (T1).

The experiment was completed in one day and was divided into nine sessions as shown in Table 1 . Out of the six subjects, only three were tested on both devices and they were given at least 1 hour rest before they received the next round of traction. The traction force was set to $20 \%$ of the subject's body weight, as suggested in previous studies [4] [5]. Traction angles $10^{\circ} / 20^{\circ} / 30^{\circ} / 40^{\circ}$ were used in the experiment.

Each session was approximately 10 minutes and it contained four sets of traction exercise. The procedures of the experiment were as follows: i) setup and ve-
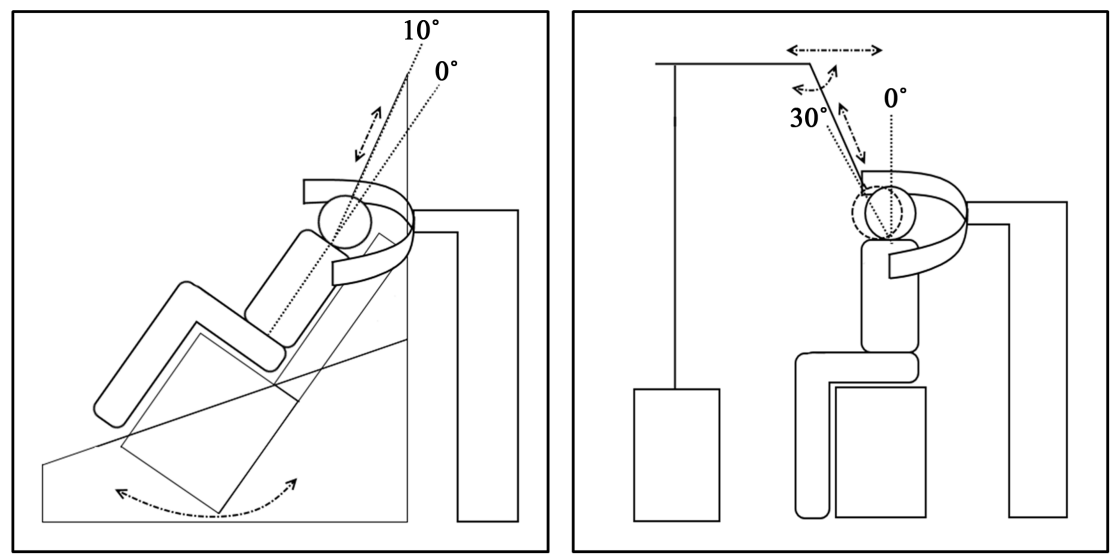

Figure 2. Experiment setup for inclined position (left) and sitting position (right). Inclined position: Rotation of the seat determines the traction angle in the inclined position, when the extension of the top bar determines the traction angle in the sitting position.

Table 1. Experiment setup.

\begin{tabular}{ccccc}
\hline \multirow{2}{*}{ Subjects } & \multicolumn{2}{c}{ Traction Positions } & & \\
\cline { 2 - 4 } & Inclined & Sitting & Traction Force & Traction Angle \\
\cline { 2 - 4 } $30 \mathrm{~A}$ & $\circ$ & Not tested & $100 \mathrm{~N}$ & $10^{\circ} / 20^{\circ} / 30^{\circ} / 40^{\circ}$ \\
$30 \mathrm{~B}$ & Not tested & 0 & $130 \mathrm{~N}$ & $10^{\circ} / 20^{\circ} / 30^{\circ} / 40^{\circ}$ \\
$50 \mathrm{~A}$ & $\circ$ & 0 & $140 \mathrm{~N}$ & $10^{\circ} / 20^{\circ} / 30^{\circ} / 40^{\circ}$ \\
$50 \mathrm{~B}$ & 0 & 0 & $150 \mathrm{~N}$ & $10^{\circ} / 20^{\circ} / 30^{\circ} / 40^{\circ}$ \\
$60 \mathrm{~A}$ & $\circ$ & 0 & $140 \mathrm{~N}$ & $10^{\circ} / 20^{\circ} / 30^{\circ} / 40^{\circ}$ \\
$60 \mathrm{~B}$ & Not tested & $\circ$ & $160 \mathrm{~N}$ & $10^{\circ} / 20^{\circ} / 30^{\circ} / 40^{\circ}$ \\
\hline
\end{tabular}


rify traction angle with the subject seated in the machine, ii) apply traction, iii) maintain continuous traction for 10 seconds, iv) release traction, v) rest and prepare for the next angle. Radiographic images were taken before and during each round of traction. The distance between the radiographic equipment and the traction device was fixed. No subject reported discomfort during and after the experiment.

\subsection{Radiographic Image Analysis}

A total of 55 radiographic images were taken during the experiment. The digitalized images were in grayscale and had a resolution of $640 \times 480$. A sample of the image is shown in Figure 3.

In order to improve the accuracy of the measurement, the low-resolution images were magnified using a technique called "image super-resolution" [11] to maximize picture quality. The anatomical identifications of the vertebral landmark were based on the method of Farfan et al. [12] [13] as shown in Equations (1) and (2).

$$
\begin{aligned}
& \text { Anterior disc height }=\frac{\left(A_{1}+A_{2}\right)}{2} \\
& \text { Posterior disc height }=\frac{\left(P_{1}+P_{2}\right)}{2}
\end{aligned}
$$

Figure 4 illustrates the modified Farfan's method used in the image analysis. $\mathrm{A} 1 / \mathrm{A} 2 / \mathrm{P} 1 / \mathrm{P} 2$ are straight lines extended from point $\mathrm{A} / \mathrm{B} / \mathrm{C} / \mathrm{D}$ and are perpendicular to the two horizontal lines joining the A-B and C-D points. The contrast and brightness level of the image were fine-tuned using Image $J$ [14] and the vertebral landmarks were then manually traced using Inkscape [15]. All the images were measured three times digitally and the mean values of the measurements were taken as the final result.

\section{Results and Analysis}

\subsection{Mean Intervertebral Separation Changes}

The mean values of anterior and posterior intervertebral disc space changes are summarized in Table 2. Space changes are the difference in C2-C7 length be-

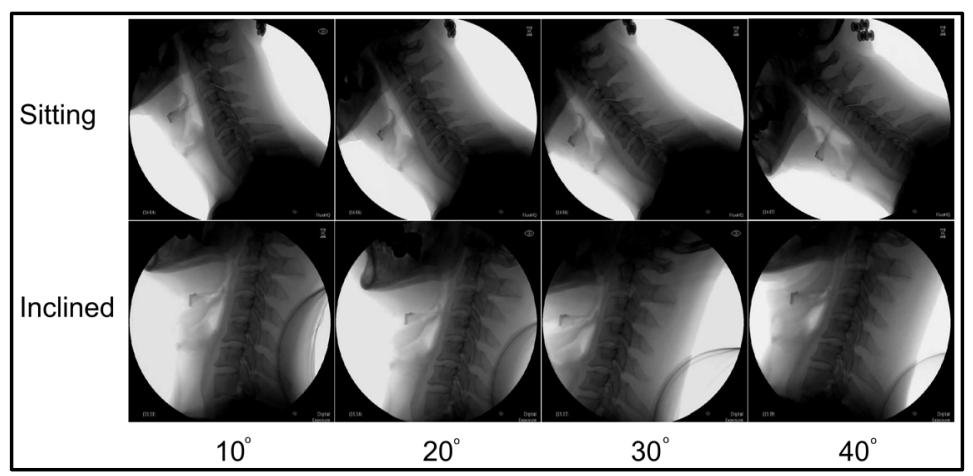

Figure 3. Radiographic images of the cervical spine taken during the experiment. 


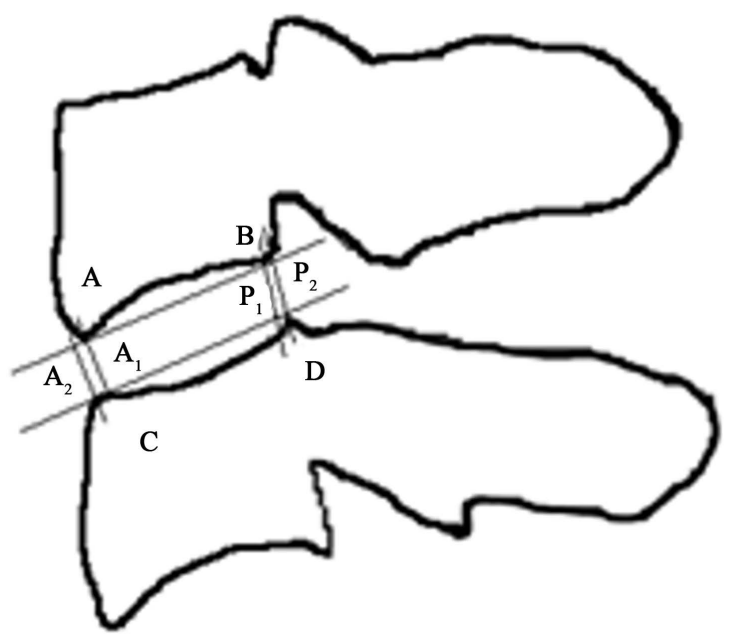

Figure 4. Measurement of disc height using a modified Farfan's method. A: anteroinferior corner of the upper vertebral body; B: posteroinferior corner of the upper vertebral body; C: anterosuperior corner of the lower vertebral body; D: posterosuperior corner of the lower vertebral body.

Table 2. Mean values of intervertebral disc spaces in inclined and sitting positions.

\begin{tabular}{|c|c|c|c|c|c|}
\hline \multirow{2}{*}{ Position $(n=3)$} & \multirow{2}{*}{ Traction Angle } & \multirow{2}{*}{ Side } & \multicolumn{2}{|c|}{ Space Change } & \multirow{2}{*}{$\begin{array}{c}\text { Paired t-test } \\
\quad P \text { value }\end{array}$} \\
\hline & & & Mean $(\mathrm{mm})$ & $\mathrm{SD}$ & \\
\hline \multirow{8}{*}{ Inclined Position } & \multirow{2}{*}{$10^{\circ}$} & Anterior & 2.528 & 0.274 & $<0.05$ \\
\hline & & Posterior & 2.025 & 0.158 & $<0.05$ \\
\hline & \multirow{2}{*}{$20^{\circ}$} & Anterior & 3.349 & 1.400 & 0.054 \\
\hline & & Posterior & 2.505 & 0.973 & $<0.05$ \\
\hline & \multirow{2}{*}{$30^{\circ}$} & Anterior & 4.562 & 1.457 & $<0.05$ \\
\hline & & Posterior & 3.759 & 0.785 & $<0.05$ \\
\hline & \multirow{2}{*}{$40^{\circ}$} & Anterior & 4.775 & 1.288 & $<0.05$ \\
\hline & & Posterior & 3.700 & 0.194 & $<0.05$ \\
\hline \multirow{8}{*}{$\begin{array}{l}\text { Sitting } \\
\text { Position }\end{array}$} & \multirow{2}{*}{$10^{\circ}$} & Anterior & 0.740 & 0.885 & 0.193 \\
\hline & & Posterior & 0.696 & 0.806 & 0.183 \\
\hline & \multirow{2}{*}{$20^{\circ}$} & Anterior & 0.978 & 0.660 & 0.059 \\
\hline & & Posterior & 0.832 & 0.858 & 0.148 \\
\hline & \multirow{2}{*}{$30^{\circ}$} & Anterior & 1.121 & 1.199 & 0.158 \\
\hline & & Posterior & 1.129 & 1.251 & 0.169 \\
\hline & \multirow{2}{*}{$40^{\circ}$} & Anterior & 1.209 & 1.213 & 0.140 \\
\hline & & Posterior & 1.889 & 1.767 & 0.122 \\
\hline
\end{tabular}

tween before traction and during traction. The data was based on the three subjects that were tested in both devices. In general, there were significant changes for most of the angles in the inclined position $(P<0.05$ for all except $P=0.054$ at $20^{\circ}$ anterior). In the sitting position, however, our results showed no statistical changes for all traction angles. 
The mean changes of the total intervertebral separations (C2-C7) of all six subjects across four different traction angles are shown in Figure 5. The inclined position yields a larger change on both the anterior and posterior sides.

\subsection{Spinal Segment Changes}

The mean intervertebral separations of each spinal segment are presented in Table 3 and Table 4.

Table 3. Mean segment changes in inclined position.

\begin{tabular}{|c|c|c|c|c|c|}
\hline \multicolumn{6}{|c|}{ Inclined Position } \\
\hline \multirow{2}{*}{ Sides } & \multirow{2}{*}{ Segment } & \multicolumn{4}{|c|}{ Traction Angles } \\
\hline & & $10^{\circ}$ & $20^{\circ}$ & $30^{\circ}$ & $40^{\circ}$ \\
\hline \multirow{6}{*}{ Anterior } & $\mathrm{C} 2 / 3$ & -0.327 & -0.051 & -0.443 & -0.343 \\
\hline & $\mathrm{C} 3 / 4$ & -0.687 & -0.820 & -0.838 & -0.957 \\
\hline & $\mathrm{C} 4 / 5$ & -0.803 & -0.930 & -1.086 & -0.833 \\
\hline & $\mathrm{C} 5 / 6$ & -0.217 & -0.656 & -0.956 & -1.088 \\
\hline & $\mathrm{C} 6 / 7$ & 0.087 & -0.396 & -0.802 & -1.211 \\
\hline & Total & -1.947 & -2.853 & -4.125 & -4.432 \\
\hline \multirow{6}{*}{ Posterior } & $\mathrm{C} 2 / 3$ & 0.562 & 0.553 & 0.646 & 0.573 \\
\hline & $\mathrm{C} 3 / 4$ & 0.458 & 0.265 & 0.444 & 0.472 \\
\hline & $\mathrm{C} 4 / 5$ & 0.408 & 0.563 & 0.848 & 0.959 \\
\hline & $\mathrm{C} 5 / 6$ & 0.221 & 0.395 & 0.600 & 0.693 \\
\hline & C6/7 & 0.159 & 0.608 & 1.079 & 0.953 \\
\hline & Total & 1.808 & 2.384 & 3.617 & 3.65 \\
\hline
\end{tabular}

Table 4. Mean segment changes in sittingposition.

\begin{tabular}{|c|c|c|c|c|c|}
\hline \multicolumn{6}{|c|}{ Sitting Position } \\
\hline \multirow{2}{*}{ Sides } & \multirow{2}{*}{ Segment } & \multicolumn{4}{|c|}{ Traction Angles } \\
\hline & & $10^{\circ}$ & $20^{\circ}$ & $30^{\circ}$ & $40^{\circ}$ \\
\hline \multirow{6}{*}{ Anterior } & $\mathrm{C} 2 / 3$ & 0.076 & 0.179 & -0.154 & -0.200 \\
\hline & $\mathrm{C} 3 / 4$ & 0.045 & -0.003 & -0.075 & -0.005 \\
\hline & $\mathrm{C} 4 / 5$ & 0.156 & 0.092 & -0.184 & -0.386 \\
\hline & $\mathrm{C} 5 / 6$ & 0.097 & -0.247 & -0.331 & -0.277 \\
\hline & C6/7 & 0.019 & -0.364 & -0.312 & -0.416 \\
\hline & Total & 0.393 & -0.343 & -1.056 & -1.284 \\
\hline \multirow{6}{*}{ Posterior } & $\mathrm{C} 2 / 3$ & 0.364 & 0.415 & 0.100 & 0.522 \\
\hline & $\mathrm{C} 3 / 4$ & 0.173 & 0.208 & 0.401 & 0.497 \\
\hline & $\mathrm{C} 4 / 5$ & 0.447 & 0.657 & 0.562 & 0.605 \\
\hline & $\mathrm{C} 5 / 6$ & 0.275 & 0.009 & 0.231 & 0.353 \\
\hline & C6/7 & -0.112 & 0.258 & 0.410 & 0.571 \\
\hline & Total & 1.147 & 1.547 & 1.704 & 2.548 \\
\hline
\end{tabular}


Mean Change of Anterior Intervertebral Separations

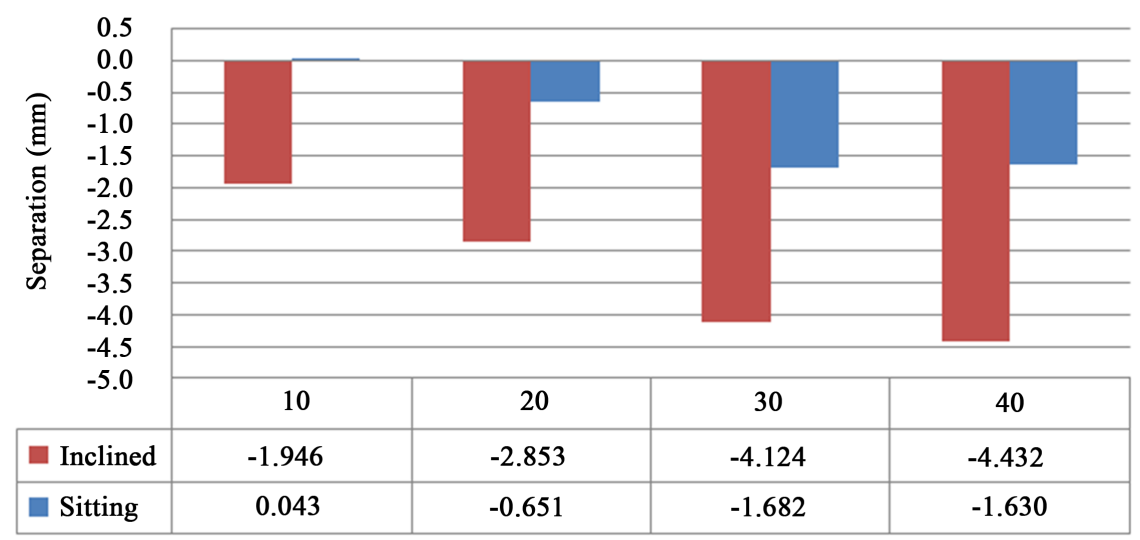

Traction Angle (Degree)

Mean Change of Anterior Intervertebral Separations

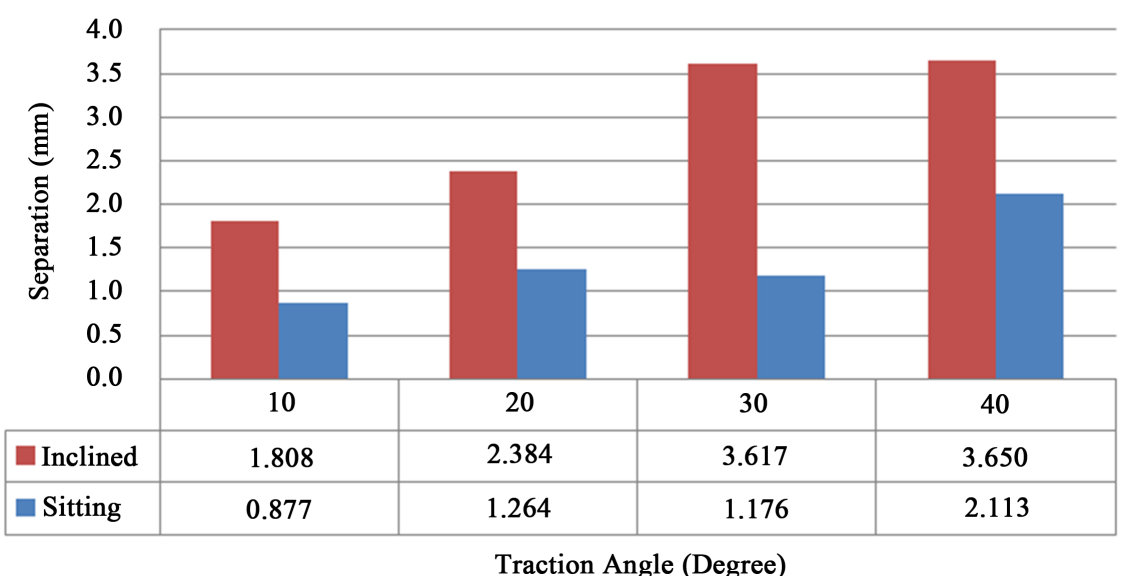

Figure 5. Mean change of C2-C7 intervertebral separations (upper: anterior; down: posterior).

In the inclined position, $10^{\circ}$ angle resulted in the largest posterior separations in the upper cervical spine and smallest in the lower spine. On the other hand, the $20^{\circ} / 30^{\circ} / 40^{\circ}$ angles followed an opposite trend, in which the separations were larger in the lower spine (C4-C7). In the sitting position, however, the mid-spine (C4-C5) extends the most regardless of the traction angles. In a past study, Ito et al. [5] examined the relationship between traction angles and segmental separations. They concluded that small traction angles can lead to large posterior separation in the upper spine, and large angles can lead to separation in the lower spine. In this experiment, we observed a similar trend in the inclined position but not in the sitting position. The segmental changes for both positions are illustrated in Figure 6.

\subsection{Shape Change Sequence of the Cervical Spine}

After the tracing of vertebral landmark was completed, we compared the outlines of the cervical spine. As illustrated in Figure 7, it appears that the cervical 

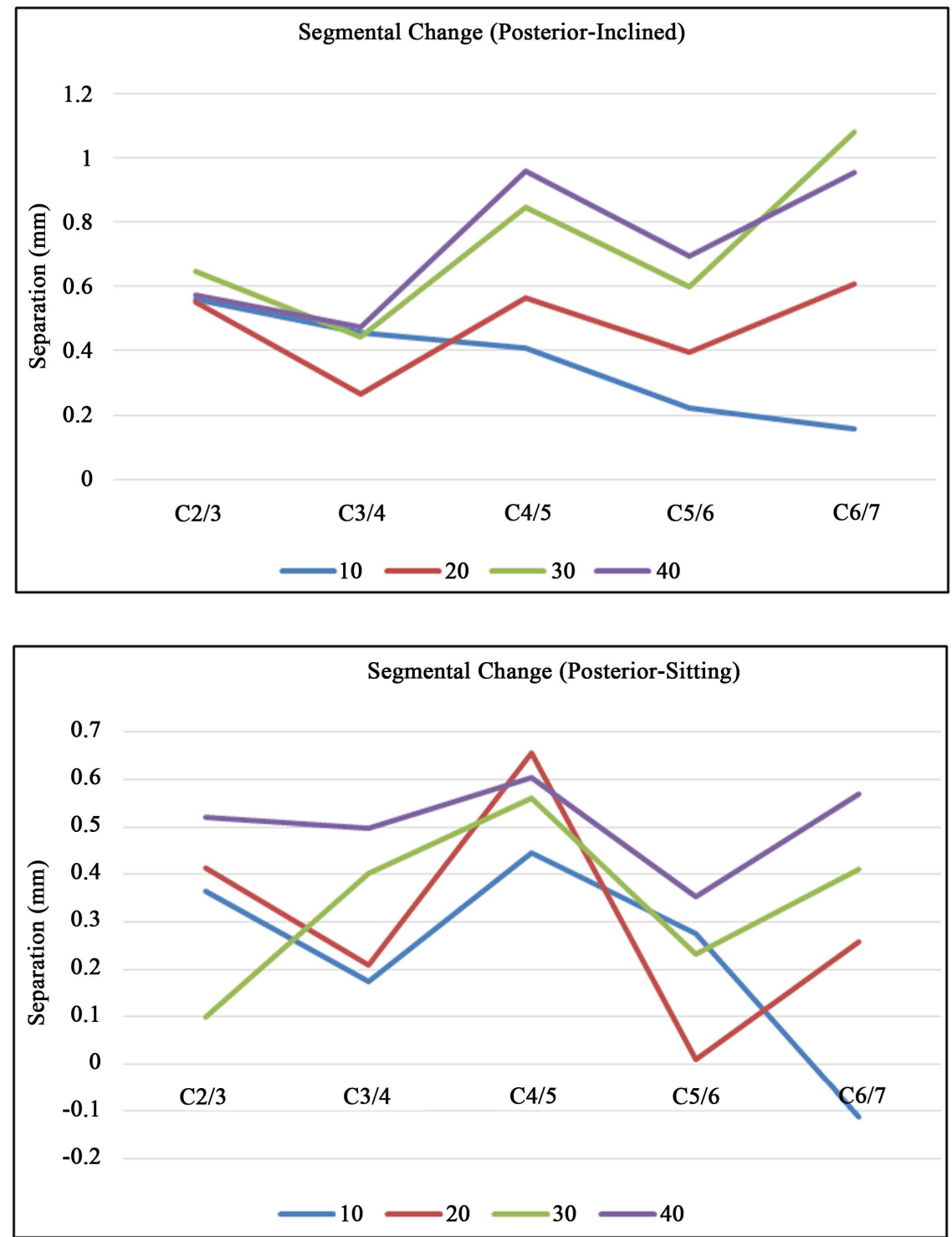

Figure 6. Posterior segmental change for inclined (upper) and sitting (down) position.
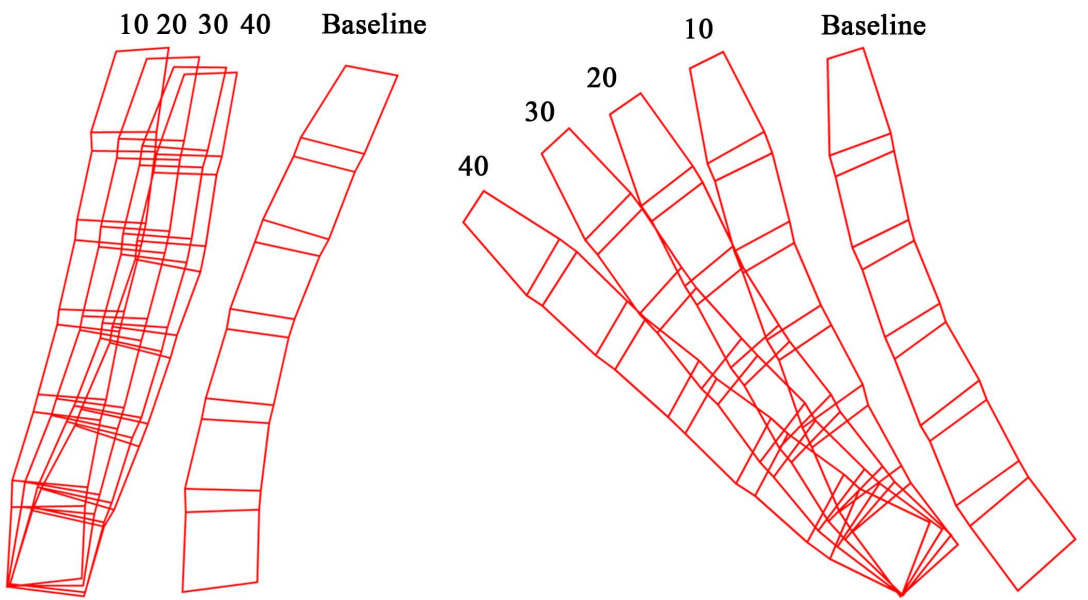

Figure 7. Traced sequence of changes of cervical spine from radiographic images in inclined (left) and sitting (right) positions. 
spine underwent different transformation with the two positions. With the rotating chair mechanism in the inclined position, the outline of the radiographic images shows only a small transformation. On the contrary, the transformation of the sitting position was comparatively larger, even though the sitting position yielded a significantly smaller mean change in both anterior and posterior sides with all traction angles. The relatively small transformation in the inclined position may have contributed to the overall improvement in the intervertebral separations.

\subsection{Age Difference vs. Intervertebral Separation Changes}

The six subjects were chosen such that their age differences in response to traction at various angles can be examined. The hypothesis was that intervertebral discs tend to lose water content in elderly subjects [16], thus it was expected that their intervertebral separations would be different from the ones in younger subjects. However, due to the limited sample size in the experiment, we were not able to detect a significant difference. Among the subjects using the inclined position, $60 \mathrm{~A}$ has the largest compression and extension, while 30A recorded the smallest changes. Conversely, data from the sitting position did not yield any significant differences between older and younger subjects.

\subsection{Disc Space Change Due to Traction Force and Angles}

Figure 8 illustrated the compression and extension of the intervertebral disc space due to traction force and angles. With inclined position, both the anterior and posterior sides exhibited a smooth transition as the force and angle increase. On the other hand, the transition was uneven for the sitting position on both sides. In fact, larger traction force actually resulted in smaller separation on the posterior side. It suggests that it is more difficult to control separations in the sitting position with traction force and angles.

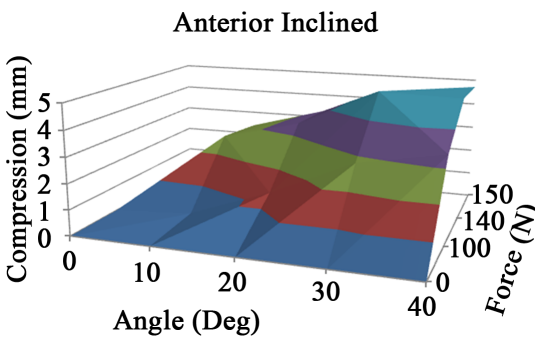

Anterior Sitting

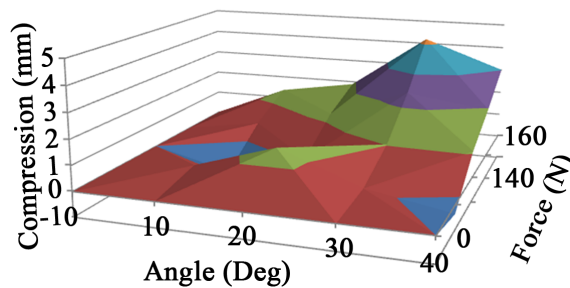

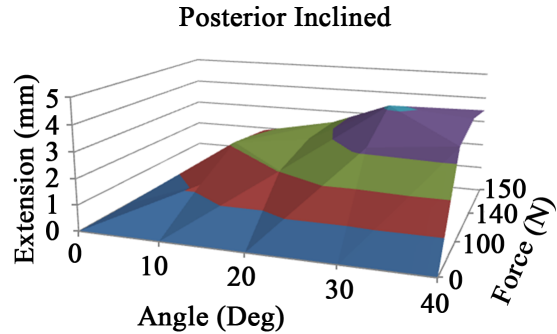

Posterior Sitting

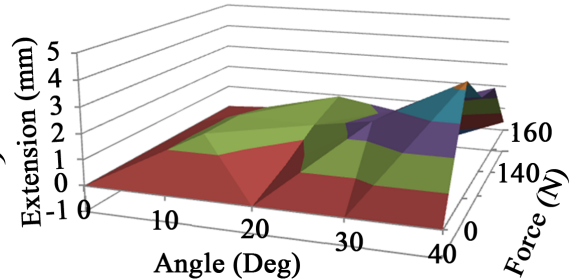

Figure 8. Comparison of intervertebral compression caused by traction force and traction angle between inclined and sitting positions. 


\section{Cervical Traction Therapy Simulation}

The cervical traction therapy simulation is a multi-body dynamic simulation model consisted of a cervical spine, a skeleton body and two mechanical traction devices, representing the inclined and sitting positions respectively. It was developed using Bullet Physics Library, an open-source physics simulation engine capable of simulating collision detection, soft and rigid body dynamics [17]. The development environment was Visual Studio 2015 and the models were written in $\mathrm{C}^{++}$.

\subsection{Cervical Spine and Skeleton Body Model}

The cervical spine model was built based on a previous in-house project [8] [18] and was re-modelled with a new physics engine for performance improvement. It consisted of a skull and seven pieces of rigid cervical vertebrae (C1-C7). C1 vertebra, also known as the atlas, was fixed to the skull. The $\mathrm{C} 2-\mathrm{C} 7$ cervical vertebrae were attached to adjacent vertebrae by a 6-DOF spring joint with stiffness and damping parameters to control their movement. The C7-T1 join was also fixed. In order to simplify the calculation, rotation and lateral flexion were disabled. Only flexion and extension were allowed. The skeleton body model included the rest of the body below the cervical spine, and was modelled as separated rigid bodies. All the $3 \mathrm{D}$ models used in this section were retrieved from BodyParts3D [19]. The body segment mass ratio was configured based on the data from Zatsiorsky et al. [20]. The body model was set to be $1.74 \mathrm{~m}$ and $73 \mathrm{~kg}$. The combined weight of the head and the cervical spine was estimated to be 5.07 $\mathrm{kg}$. The mass of the body segments is listed in Table 5.

\subsection{Mechanical Traction Device Model}

Similar to the skeleton model, the two traction device models were also built using Visual Studio, $\mathrm{C}^{++}$and the Bullet Physics Library. The dimensions and the mechanical movement of the device models followed the same traction devices [9] [10] used in the radiographic experiment and they represented the inclined and sitting positions. Figure 9 shows the inclined and sitting position simulation models at $10^{\circ}$ and $40^{\circ}$ traction.

Table 5. Body segment mass.

\begin{tabular}{ccc}
\hline Bone Names & Percentage of Body Weight (\%) & Mass $(\mathbf{k g})$ \\
\hline Head + Neck & 6.94 & 5.07 \\
Upper + Mid Trunk & 32.29 & 23.57 \\
Lower Trunk (pelvis) & 11.17 & 8.15 \\
Upper Arms & $2.71 \times 2$ & $1.98 \times 2$ \\
Forearms + Hands & $2.23 \times 2$ & $1.63 \times 2$ \\
Thighs & $14.16 \times 2$ & $10.34 \times 2$ \\
Shanks + Feet & $5.70 \times 2$ & $4.16 \times 2$ \\
Total & $100 \%$ & 73.0 \\
\hline
\end{tabular}

^based on Zatsiorsky et al. [20]. 

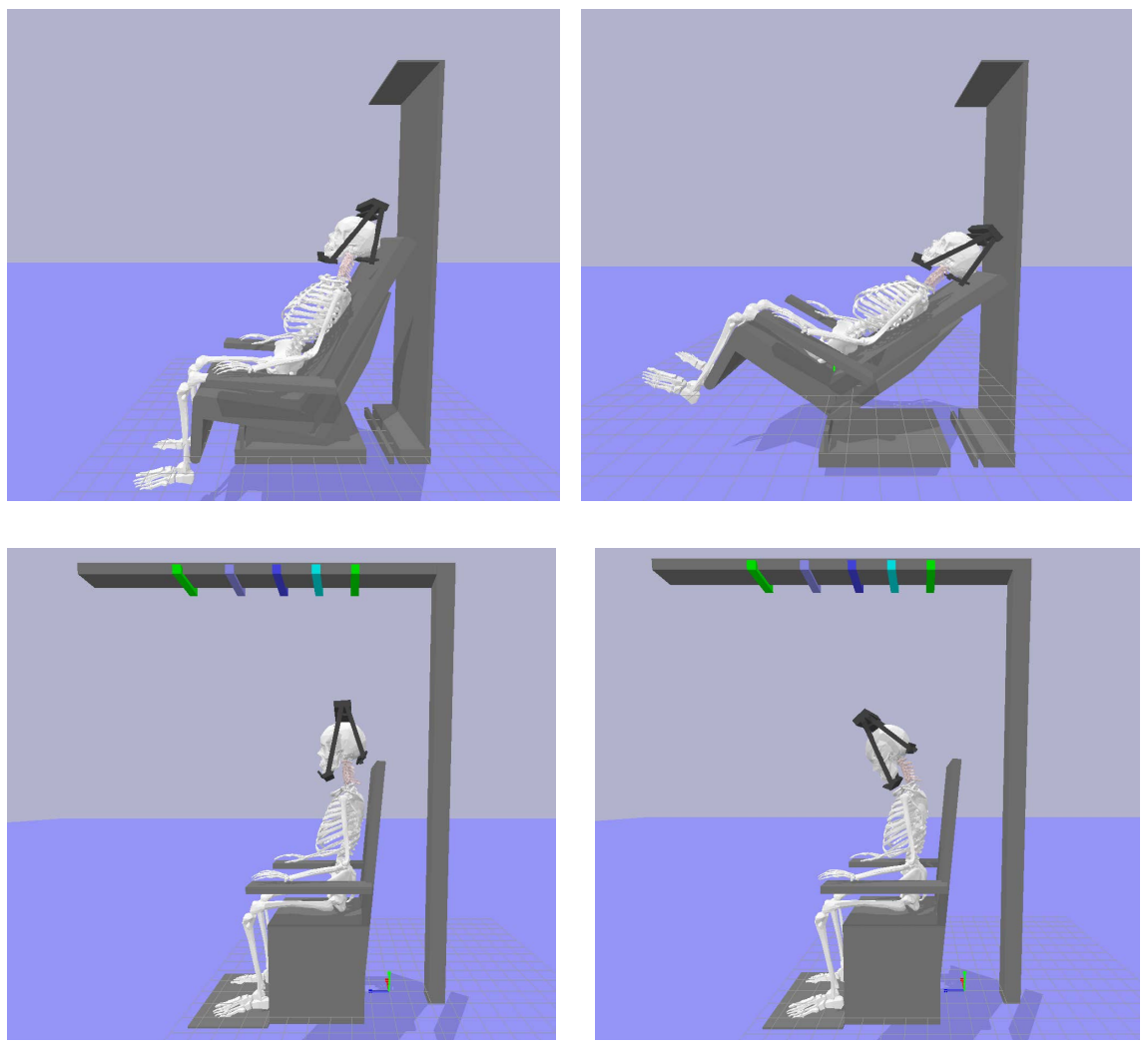

Figure 9. Cervical traction simulation models. (top-left: inclined $10^{\circ}$, top-right: inclined $40^{\circ}$, bottom-left: sitting $10^{\circ}$, bottom-right: sitting $40^{\circ}$ ).

\section{Simulation Model and Results}

The data from the radiographic experiment, as shown in Table 3 and Table 4, was applied to the cervical spine spring-damper model. Each space between the vertebrae (C2-C7) contains a 6-DOF spring joint that controls vertical movement, flexion and extension. We calculated the mean value of the stiffness and damping constants based on the six subjects and apply them to both models. Simulation trials were performed using the same combinations of traction angles, forces and positions as in the experiment. In each run, both the anterior and posterior intervertebral separations between $\mathrm{C} 2-\mathrm{C} 7$ vertebrae were measured. Traction angles at $10^{\circ} / 20^{\circ} / 30^{\circ} / 40^{\circ}$ were tested. The traction force was set to be $20 \%$ of the skeleton, which yields $144 \mathrm{~N}$. Both positions were tested under the same setup, i.e. all the material properties, stiffness and damping parameters of the mechanical joints were the same in both simulations. The measured separations represent the changes of separation before and after traction applied. The simulation results are shown in Figure 10.

The simulation result followed a similar trend as the mean measurements from the experiment. As in the experiment result, the result of the simulation also suggested that the inclined position could achieve larger amount of intervertebral separation and compression than the sitting position. In scenarios where large traction angles were used, the sitting position always caused the skeleton to lean forward to compensate for the pulling force. This was not observed 

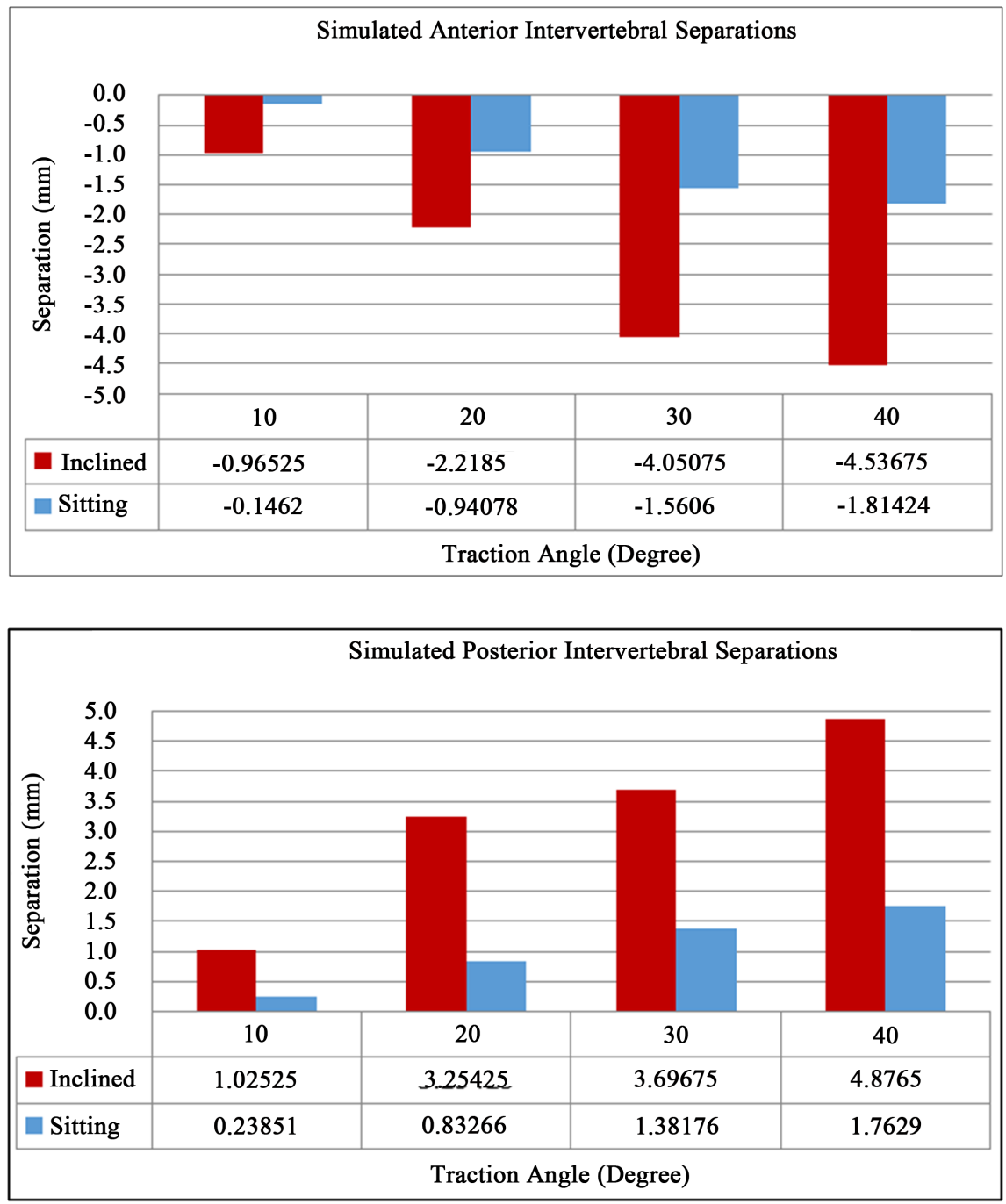

Figure 10. Simulated result of C2-C7 intervertebral separations (upper: anterior, down: posterior).

in the inclined position in our simulation. Furthermore, the inclined position was also better in achieving the desired traction angle, since the back of the skeleton body remained in contact with the back of the seat. This helped the traction angle stay the same throughout the session of the traction simulation.

\section{Conclusion and Future Work}

In our previous study, a cervical traction therapy simulation model was constructed to investigate the biomechanical changes of the cervical spine during traction therapy. The model was also used to evaluate the differences between the inclined and sitting traction positions. However, the lack of clinical data in the study significantly limits the potentials of the model. The present study aimed to address this problem by conducting a radiographic study to gather data of the cervical intervertebral changes during traction therapy. Six subjects participated in our experiment to receive traction on two actual traction devices. Radiographic images of their cervical spines were taken before and during the 
therapy and the resulting intervertebral disc changes were used to improve the existing cervical traction therapy simulation model. The new model verified the previous findings and again demonstrated that the inclined position was able to achieve larger intervertebral space changes than the sitting position both anteriorly and posteriorly. The spinal segmental changes between C2-C7 also suggested that the inclined position provided better control in positioning the intervertebral separation in different area of the cervical spine.

There were few limitations in this study that the authors would like to address in future works. With only 10 seconds of traction at each angle, this study did not take into account of the residual effect of the intervertebral discs caused by long period of traction. Due to this limitation, we were not able to observe the disc changes that may occur in intermittent traction. In addition, the small sample size of the experiment may affect the accuracy of the result. Thus, it is essential to expand the experiment to gather larger clinical data and create a more comprehensive simulation model.

\section{References}

[1] Savva, C. and Giakas, G. (2013) The Effect of Cervical Traction Combined with Neural Mobilization on Pain and Disability in Cervical Radiculopathy. A Case Re-port. Manual Therapy, 18, 443-446. https://doi.org/10.1016/j.math.2012.06.012

[2] Jellad, A., Ben Salah, Z., Boudokhane, S., Migaou, H., Bahri, I. and Rejeb, N. (2009) The Value of Intermittent Cervical Traction in Recent Cervical Radiculopathy. Annals of Physical and Rehabilitation Medicine, 52, 638-652. https://doi.org/10.1016/j.rehab.2009.07.035

[3] Zylbergold, R. and Piper, M. (1985) Cervical Spine Disorders: A Comparison of Three Types of Traction. Spine, 10, 867-871. https://doi.org/10.1097/00007632-198512000-00001

[4] Wong, A., Leong, C. and Chen, C. (1992) The Traction Angle and Cervical Interver-tebral Separation. Spine, 17, 136-138. https://doi.org/10.1097/00007632-199202000-00003

[5] Ito, F. and Kiyama, T. (1985). Angular Factor in Intermittent Cervical Traction. Sogo Rehabilitation, 13, 213-218.

[6] Chung, C.-T., Tsai, S.-W., Chen, C.-J., Wu, T.-C., Wang, D., Lan, H.-C.H. and Wu, S.-K. (2009) Comparison of the Intervertebral Disc Spaces between Axial and Anterior Lean Cervical Traction. European Spine Journal, 18, 1669-1676.

https://doi.org/10.1007/s00586-009-1072-Z

[7] Fater, D.C.W. and Kernozek, T.W. (2008) Comparison of Cervical Vertebral Separation in the Supine and Seated Positions Using Home Traction Units. Physiotherapy Theory and Practice, 24, 430-436. https://doi.org/10.1080/09593980802511896

[8] Wong, L.K., Luo, Z. and Kurusu, N. (2014) Dynamic Simulation of Cervical Traction Therapy: Comparison between Sitting and Inclined Positions. Robotics and Biomimetics (ROBIO), 2014 IEEE International Conference on IEEE, Bali, 5-10 December 2014, 167-172.

[9] Tractizer Model TC-30D (2005) Minato Medical Science, Japan. http://www.minato-med.co.jp/medical/products/physical/tc.php

[10] Tractizer Model TC-C1 (2014) Minato Medical Science, Japan. 
http://www.minato-med.co.jp/medical/products/physical/tcc1.php

[11] Dong, C., Loy, C., He, K. and Tang, X. (2016) Image Super-Resolution Using Deep Convolutional Networks. IEEE Transactions on Pattern Analysis and Machine Intelligence, 38, 295-307. https://doi.org/10.1109/TPAMI.2015.2439281

[12] Dabbs, V.M. and Dabbs, L.G. (1990) Correlation between Disc Height Narrowing and Low-Back Pain. Spine, 15, 1366-1369. https://doi.org/10.1097/00007632-199012000-00026

[13] Martins, D.E., De Oliveira, V.M., Alves, M.T.D.S., Wajchenberg, M., Landim, E., Belloti, J.C., Puertas, E.B. and Ishida, A. (2010) Correlations between Radiographic, Magnetic Resonance and Histological Examinations on the Degeneration of Human Lumbar Intervertebral Discs. Sao Paulo Medical Journal, 128, 63-68. https://doi.org/10.1590/S1516-31802010000200004

[14] ImageJ 1.51. (2016) https://imagej.nih.gov/ij/

[15] Inkscape 0.91. (2016) https://inkscape.org/en/

[16] Ferguson S.J. and Steffen, T. (2003) Biomechanics of the Aging Spine. European Spine Journal, 12, S97-S103. https://doi.org/10.1007/s00586-003-0621-0

[17] Bullet Physics Library 2.85. (2016) http://bulletphysics.org

[18] Wong, L.K., Luo, Z., Kurusu, N. and Fujino, K. (2013) Cervical Spine Simulation Model for Traction Therapy Analysis. Proceedings of the 2013 IEEE/SICE International Symposium on System Integration, Kobe, 15-17 December 2013, 516-520. https://doi.org/10.1109/SII.2013.6776747

[19] BodyParts3D/Anatomography (2008) Database Center for Life Science, Licensed by CC-BY-SA-2.1-jp. http://lifesciencedb.jp/bp3d/

[20] De Leva, P. (1996) Adjustments to Zatsiorsky-Seluyanov's Segment Inertia Parame-ters. Journal of Biomechanics, 29, 1223-1230. https://doi.org/10.1016/0021-9290(95)00178-6

Scientific Research Publishing

\section{Submit or recommend next manuscript to SCIRP and we will provide best service for you:}

Accepting pre-submission inquiries through Email, Facebook, LinkedIn, Twitter, etc. A wide selection of journals (inclusive of 9 subjects, more than 200 journals)

Providing 24-hour high-quality service

User-friendly online submission system

Fair and swift peer-review system

Efficient typesetting and proofreading procedure

Display of the result of downloads and visits, as well as the number of cited articles

Maximum dissemination of your research work

Submit your manuscript at: http://papersubmission.scirp.org/

Or contact ojtr@scirp.org 